\title{
The efficacy of pulmonary thromboendarterectomy on long-term gas exchange
}

\author{
N. Tanabe*, O. Okada*, Y. Nakagawa**, M. Masuda**, K. Kato*, N. Nakajima**, T. Kuriyama*
}

The efficacy of pulmonary thromboendarterectomy on long-term gas exchange. N. Tanabe, O. Okada, Y. Nakagawa, M. Masuda, K. Kato, N. Nakajima, T. Kuriyama. (CERS Journals Ltd 1997.

ABSTRACT: It has not been delineated in detail how pulmonary thromboendarterectomy (PTE) affects gas exchange through long-term follow-up. In Japan, this surgery has been undertaken in a limited number of institutions, and the results of PTE have not been well publicized.

A total of 25 patients were operated on during the period from 1985 to 1996 at our institution, and the overall mortality rate was $16 \%$. Our criteria for PTE were based on the following: 1) thrombi surgically accessible as judged by angiographic study; 2) mean pulmonary arterial pressure $\geq 30 \mathrm{mmHg}$. The efficacies of PTE were analysed on haemodynamics as well as gas exchange at one month postsurgery and during follow-up (6-24 months).

Significant haemodynamic improvement was obtained as early as 1 month after surgery. Improvement of gas exchange lagged, but was then observed during follow-up, and the improvement level of pulmonary haemodynamics was sustained. The early postoperative restrictive impairment and ventilation-perfusion abnormality on lung perfusion scan resolved during the follow-up period.

It was concluded that the early postoperative efficacy of pulmonary thromboendarterectomy was mainly achieved due to the reduction of pulmonary hypertension, whereas improvement in gas exchange was obtained over the longer term. Eur Respir J 1997; 10: 2066-2072.
*Dept of Chest Medicine and **First Dept of Surgery, Chiba University School of Medicine, Chiba 260, Japan.

Correspondence: N. Tanabe Dept of Chest Medicine Chiba University School of Medicine 1-8-1 Inohana Chuou-ku Chiba 260 Japan

Keywords: Gas exchange pulmonary hypertension pulmonary thromboendarterectomy

Received: March 111997

Accepted after revision July 41997
Although the incidence of chronic thromboembolic pulmonary hypertension (CTEPH) is thought to be rare, and the disorder is considered resistant to medical treatment, it has been demonstrated that it can be cured by means of pulmonary thromboendarterectomy (PTE) [119]. The annual incidence of pulmonary thromboembolism in Japan has been increasing, according to autopsy reports, but is still only about $10 \%$ of the frequency in Western countries [20]. Surgery for chronic pulmonary thromboembolism was first firmly established at the University of California, San Diego Medical Center. Over 800 cases have been treated [7]. Search of the literature has revealed that only a few other institutions have been undertaking this surgery, and a total of a little over 1,000 operations have been recorded worldwide [1-19]. However, the mechanism by which PTE affects gas exchange through long-term follow-up has not been described in detail. In Japan, this has been carried out in a limited number of institutions [13-17], and thus, the outcome of surgery has not been well publicized. In the present report, we deal with our surgical results for CTEPH, especially in reference to the efficacy of this procedure on gas exchange in the followup period, as well as a retrospective analysis of the preoperative risk factors affecting PTE.

\section{Patients and methods}

Between April 1985 and March 1996, 39 patients were evaluated for CTEPH at Chiba University Hos- pital, Japan. CTEPH was defined as mean pulmonary arterial pressure $\left(\bar{P}_{\mathrm{pa}}\right) \geq 2.7 \mathrm{kPa}(20 \mathrm{mmHg})$ with mean pulmonary wedge pressure below $1.6 \mathrm{kPa}(12 \mathrm{mmHg})$ in patients who had dyspnoea on exertion for a duration of more than 6 months. In addition, lung perfusion scan was needed to show segmental or larger defect concomitant with normal ventilation scan study. Finally, thromboembolic obstruction was confirmed by pulmonary angiograms [21]. From 1985 to 1989, all patients received thrombolytic therapy (urokinase or tissue plasminogen activator). Since 1990, patients whose last identified episodes of pulmonary embolism were within 6 weeks before diagnosis at our hospital received thrombolytic therapy (tissue plasminogen activator). Finally, 28 of 39 patients (17 of 25 operated patients) received thrombolytic therapy. When patients showed improvements in pulmonary haemodynamics and the findings of pulmonary angiograms, they were re-evaluated after oral anticoagulant therapy for more than 6 months.

The criteria of surgical candidates for PTE were slightly modified from those defined by the San Diego group [5]. Our criteria were as follows: 1) $\bar{P}$ pa $\geq 4.0 \mathrm{kPa}$ (30 $\mathrm{mmHg}$ ), resulting in calculated pulmonary vascular resistance $(\mathrm{PVR})>300 \mathrm{dyn} \cdot \mathrm{s} \cdot \mathrm{cm}^{-5}$ even after oral anticoagulant therapy for more than 6 months; 2) dyspnoea on exertion according to Fletcher and Hugh-Jones $(\mathrm{H}-$ J) classification grade $\geq 3$ [22]; 3) thrombi defined as accessible to current surgical technique (main, lobar, segmental arteries); and 4) the absence of severe associated disease. Among the total of 39 patients whose 
diagnosis was confirmed as CTEPH, nine patients were eliminated because of problems regarding the criteria. Out of 30 patients, 25 patients, along with their families, accepted the surgical risks, and underwent surgery.

\section{Operative approach}

In 16 cases, we used a lateral thoracotomy approach [10-18] to one lung where the dominant finding existed according to ventilation-perfusion scans and pulmonary arteriogram. We did not introduce a median sternotomy technique until 1990. The first seven patients were treated by unilateral thoracotomy approach. Two of these seven cases were reoperated on the opposite side 3 months later as a staged procedure. Even after 1990, nine cases were operated on by unilateral thoracotomy approach, because thrombi on the contralateral side were judged to be located in the subsegmental arteries and/or a few segmental arteries.

In nine cases, we used a median sternotomy approach under total cardiopulmonary bypass (CPB) with deep hypothermia and circulatory arrest technique [1-9]. In six of these nine cases, endarterectomy was mainly treated in only one lung (five cases in right lung, one case in left lung), because thrombi on the contralateral side were located "too distal" [19], were too fragile to be retracted, and/or a few thrombi existed in segmental arteries. The remaining three cases were endarterectomized bilaterally.

As for the time course, 14 patients (three with median with CPB; 11 with lateral thoracotomy) were operated on between 1986 and 1991, and 11 (six with median with CPB; five with lateral thoracotomy) were operated on from 1992.

In all patients, inferior vena cava filters were placed postoperatively, unless a previous interruptive procedure had been done.

\section{Analysis}

Pulmonary haemodynamics, gas-exchange, pulmonary function data, and H-J classification were compared before and 1 month after surgery, and during the follow-up period (6-24 months). In the two cases of staged surgeries, follow-up data were obtained 6 and 18 months, after the second surgery.

To assess the effectiveness of surgery, we classified survivors into two groups (excellent results group: decrease in PVR $>30 \%$ and increase in arterial oxygen tension $\left(P \mathrm{a}, \mathrm{O}_{2}\right)>10$ torr compared to preoperative data; moderate results group: decrease in PVR $\leq 30 \%$ and/or $P \mathrm{a}, \mathrm{O}_{2}$ increase $\leq 10$ torr). We defined the moderate results group and nonsurvivors as the poor results group. Various preoperative parameters including age, duration of symptoms, H-J, and cardiorespiratory variables were compared between survivors and nonsurvivors and between the excellent and poor results groups during follow-up to evaluate preoperative risk factors. Mortality as well as the incidence of poor results were compared between the group with severe preoperative pulmonary hypertension $(\mathrm{PH})$ (severe PH: PVR $>900$ dyn $\cdot \mathrm{s} \cdot \mathrm{cm}^{-5}$ ) and that with moderate preoperative PH (moderate PH: PVR $\leq 900 \mathrm{dyn} \cdot \mathrm{s} \cdot \mathrm{cm}^{-5}$ ).

\section{Statistical analysis}

Comparisons of various cardiorespiratory functional data between preoperative and early postoperative, and between early postoperative and long-term follow-up periods were made using two-tailed paired t-tests. The chi-squared test was used for the comparison of preoperative H-J between the excellent and poor results groups. Comparisons of preoperative parameters between excellent and poor results groups and between survivors and nonsurvivors were made using unpaired t-tests. The Fisher's exact probability test was used to compare the incidence of poor results and mortality rate between the severe $\mathrm{PH}$ and moderate $\mathrm{PH}$ groups. A p-value of less than 0.05 was considered significant.

\section{Results}

The major characteristics of the operated patients are listed in table 1. Female patients outnumbered male patients by $1.8: 1$. The ages varied from $22-73$ yrs, with a mean \pm SD of $51 \pm 13$. The time interval from the onset of symptoms to surgery varied 6-84 months (median: 20; mean: $28 \pm 22$ ). Eleven patients $(44 \%)$ had a history of embolic episodes, while the remainder had no such

Table. 1 - Characteristics of patients who underwent thromboendarterectomy $(\mathrm{n}=25)$

\begin{tabular}{|c|c|}
\hline \multicolumn{2}{|l|}{ Characteristic } \\
\hline \multicolumn{2}{|l|}{ Age yrs } \\
\hline Mean & $51 \pm 13$ \\
\hline Range & $22-73$ \\
\hline \multirow{2}{*}{$\begin{array}{ll}\text { Gender } \mathrm{M} / \mathrm{F} & \mathrm{n} \\
& \%\end{array}$} & $9 / 16$ \\
\hline & $36 / 64$ \\
\hline \multicolumn{2}{|l|}{ Duration of symptoms months } \\
\hline Mean & $28 \pm 22$ \\
\hline Median (range) & $20(6-84)$ \\
\hline \multicolumn{2}{|l|}{ Type of clinical presentation $\mathrm{n}(\%)$} \\
\hline Recurrent & $11(44)$ \\
\hline Occult & 14 \\
\hline \multicolumn{2}{|l|}{ Severity of symptoms (H-J) n } \\
\hline Grade 2 & 1 \\
\hline Grade 3 & 11 \\
\hline Grade 4 & 10 \\
\hline Grade 5 & 3 \\
\hline \multicolumn{2}{|l|}{ NYHA class $n$} \\
\hline Class 2 & 2 \\
\hline Class 3 & 18 \\
\hline Class 4 & 5 \\
\hline \multicolumn{2}{|l|}{ Underlying disease $\mathrm{n}(\%)$} \\
\hline Deep vein thrombosis & $9(36)$ \\
\hline Varicose veins & 7 \\
\hline Positive anticardiolipin antibody & $\begin{array}{l}6 \text { of } 24 \text { tested } \\
\text { patients }(25)\end{array}$ \\
\hline Pelvic surgery & 5 \\
\hline Lower limb injury & 2 \\
\hline \multicolumn{2}{|l|}{ Pulmonary haemodynamics } \\
\hline $\bar{P}_{\mathrm{pa}} \mathrm{mmHg}$ & $47 \pm 8$ \\
\hline CI $\mathrm{L} \cdot \mathrm{min} \cdot \mathrm{m}^{-2}$ & $2.5 \pm 0.5$ \\
\hline PVR dyn $\cdot \mathrm{s} \cdot \mathrm{cm}^{-5}$ & $880 \pm 350$ \\
\hline
\end{tabular}

Values are presented as mean \pm SD, unless otherwise stated. Duration of symptoms: duration of symptoms between onset and operation; Recurrent: history of embolic episodes; Occult: no history of embolic episodes; H-J: Fletcher and Hugh-Jones classification; NYHA class: New York Heart Association functional class; $\bar{P}_{\text {pa: }}$ mean pulmonary arterial pressure; CI: cardiac index; PVR: pulmonary vascular resistance. 
history but only complained of insidious onset of dyspnoea on exertion. All but one patient were classified with an $\mathrm{H}-\mathrm{J}$ grade $\geq 3$. All but two patients belonged to functional class 3 or 4 as defined by the New York Heart Association (NYHA). Right heart catheterization revealed markedly elevated pulmonary arterial pressure,

Table 2. - Preoperative gas-exchange and pulmonary function data $(\mathrm{n}=25)$

\begin{tabular}{llc}
\hline $\mathrm{Pa}_{\mathrm{a}} \mathrm{O}_{2}$ & $\mathrm{kPa}$ & $7.6 \pm 1.1$ \\
$\mathrm{~Pa}_{2}, \mathrm{O}_{2}, \mathrm{st}$ & $\mathrm{kPa}$ & $6.3 \pm 1.5$ \\
$\mathrm{~Pa}_{\mathrm{a}, \mathrm{CO}_{2}}$ & $\mathrm{kPa}$ & $4.6 \pm 0.6$ \\
$P \mathrm{kP}-\mathrm{a}, \mathrm{O}_{2}$ & $\mathrm{kPa}$ & $6.6 \pm 1.6$ \\
$P \mathrm{v}, \mathrm{O}_{2}$ & $\mathrm{kPa}$ & $4.3 \pm 0.5$ \\
$\mathrm{Absolute}$ shunt & $\%$ & $10 \pm 4$ \\
$\mathrm{VC}$ & $\%$ pred & $99 \pm 14$ \\
$\mathrm{FEV} 1 / \mathrm{FVC}$ & $\%$ & $76 \pm 8$ \\
$\mathrm{TLC}$ & $\%$ pred & $100 \pm 17$ \\
$\mathrm{FRC}$ & $\%$ pred & $102 \pm 16$ \\
$T \mathrm{~L}, \mathrm{CO}$ & $\%$ pred & $56 \pm 18$ \\
\hline
\end{tabular}

Values are presented as mean $\pm \mathrm{SD} . \mathrm{Pa}_{\mathrm{a}} \mathrm{O}_{2}$ : arterial oxygen tension; $P \mathrm{a}, \mathrm{O}_{2}, \mathrm{st}$ : standard $\mathrm{Pa}_{\mathrm{a}} \mathrm{O}_{2} ; \mathrm{Pa}_{\mathrm{a}} \mathrm{CO}_{2}$ : arterial carbon dioxide tension; $P \mathrm{~A}-\mathrm{a}, \mathrm{O}_{2}$ : alveolar-arterial oxygen tension difference; $P_{\overline{\mathrm{v}}, \mathrm{O}_{2}}$ : mixed venous oxygen tension; VC: vital capacity; FEV1: forced expiratory volume in one second; FVC: forced vital capacity; TLC: total lung capacity; FRC: functional residual capacity; TL,CO: transfer factor of lung for carbon monoxide. $1 \mathrm{kPa}=0.133 \mathrm{mmHg}$

Table 3. - Pulmonary haemodynamics before and at 1 month after thromboendarterectomy in 20 patients in whom postoperative values were obtained

\begin{tabular}{llccc}
\hline & & $\begin{array}{c}\text { Before } \\
\text { surgery }\end{array}$ & $\begin{array}{c}1 \text { month after } \\
\text { surgery }\end{array}$ & p-value* \\
\hline $\bar{P}_{\mathrm{pa}}$ & $\mathrm{mmHg}$ & $45 \pm 7$ & $30 \pm 9$ & $<0.0001$ \\
$\mathrm{CI}$ & $\mathrm{L} \cdot \mathrm{min}^{-1} \cdot \mathrm{m}^{-2}$ & $2.6 \pm 0.5$ & $3.3 \pm 0.6$ & $<0.0001$ \\
PVR & dyn $\cdot \mathrm{s} \cdot \mathrm{cm}^{-5}$ & $781 \pm 290$ & $399 \pm 177$ & $<0.0001$ \\
\hline
\end{tabular}

Values are presented as mean \pm SD. *: two-tailed paired t-tests. For abbreviations see legend to table $1.1 \mathrm{kPa}=0.133 \mathrm{mmHg}$. reduced cardiac index $(\mathrm{CI})$, and elevated PVR in all patients. Nine patients $(36 \%)$ had a history of deep vein thrombosis. Seven patients had varicose veins in the lower limb and five patients had a history of pelvic surgery. Six of 24 patients $(25 \%)$ who were tested, had anticardiolipin antibody [23]. Perfusion scan showed various patterns of defects from segmental to unilateral with normal ventilation scan, but pulmonary angiograms showed typical chronic thromboembolic patterns [21] in all of the patients.

\section{Preoperative data}

Preoperative pulmonary haemodynamics and gas exchange data are listed in tables 1 and 2. $\bar{P}$ pa was $47 \pm 8$ $\mathrm{mmHg}$, and PVR was $880 \pm 350 \mathrm{dyn} \cdot \mathrm{s} \cdot \mathrm{cm}^{-5}$. Hypoxaemia with hypocapnia $\left(\mathrm{Pa}_{\mathrm{a}} \mathrm{O}_{2}: 7.6 \pm 1.1 \mathrm{kPa}(57 \pm 8 \mathrm{mmHg})\right.$; arterial carbon dioxide tension $\left(P \mathrm{a}, \mathrm{CO}_{2}\right): 4.6 \pm 0.6 \mathrm{kPa}(34 \pm 5$ $\mathrm{mmHg})$ ) was observed. The measured $\mathrm{Pa}_{\mathrm{a}} \mathrm{O}_{2}$ was standardized to a $\mathrm{Pa}_{\mathrm{a}} \mathrm{CO}_{2}$ level of $5.3 \mathrm{kPa}(40 \mathrm{mmHg})$ to obtain standard $\mathrm{Pa}_{\mathrm{a}} \mathrm{O}_{2}\left(\mathrm{~Pa}_{\mathrm{a}} \mathrm{O}_{2}, \mathrm{st}\right)$ by the following formula: $P \mathrm{a}, \mathrm{O}_{2}, \mathrm{st}=\left(\left(\mathrm{Pa}_{\mathrm{a}} \mathrm{CO}_{2} \times 1.66\right)+P \mathrm{a}, \mathrm{O}_{2}\right)-66.4$ [24]. Finally, all patients were hypoxaemic $\left(\mathrm{Pa}, \mathrm{O}_{2}, \mathrm{st}<9.3 \mathrm{kPa}(70 \mathrm{mmHg})\right.$. Alveolar-arterial oxygen tension difference $\left(P \mathrm{~A}-\mathrm{a}, \mathrm{O}_{2}\right)$ was elevated to $6.6 \pm 1.6 \mathrm{kPa}(49 \pm 12 \mathrm{mmHg})$. Mixed venous oxygen tension $\left(P \overline{\mathrm{v}}, \mathrm{O}_{2}\right)$ was also reduced $(4.3 \pm$ $0.5 \mathrm{kPa}(33 \pm 4 \mathrm{mmHg}))$. Absolute shunt ratio during $100 \% \mathrm{O}_{2}$ breathing $(10 \pm 4 \%)$ was somewhat higher than expected. Pulmonary function tests revealed minimal abnormalities. The transfer factor of the lung for carbon monoxide ( $T$ L,CO) was decreased to $56 \pm 18 \%$ pred.

\section{Early postoperative period}

Early postoperative catheterization was performed in 20 of 21 survivors. Significant haemodynamic improvement was observed (table 3 ). $\bar{P}$ pa decreased from $45 \pm 7 \mathrm{mmHg}$ to $30 \pm 9 \mathrm{mmHg}$. CI increased from $2.6 \pm 0.5$

Table 4. - Cardiorespiratory variables, pulmonary function data, and H-J classification before surgery, at 1 month after surgery, and during follow-up (6-24 months after surgery)

\begin{tabular}{|c|c|c|c|c|c|c|c|}
\hline & & $\begin{array}{c}\text { Patients } \\
n\end{array}$ & $\begin{array}{l}\text { Before } \\
\text { surgery } \\
1\end{array}$ & $\begin{array}{c}1 \text { month } \\
\text { after surgery } \\
2\end{array}$ & $\begin{array}{l}6-24 \text { months } \\
\text { after surgery } \\
3\end{array}$ & $\begin{array}{c}\text { p-value* } \\
1 \text { vs } 2\end{array}$ & $\begin{array}{c}\text { p-value* } \\
2 \text { vs } 3\end{array}$ \\
\hline $\bar{P}_{\mathrm{pa}}$ & $\mathrm{mmHg}$ & 11 & $44 \pm 4$ & $30 \pm 8$ & $28 \pm 9$ & $<0.0001$ & 0.17 \\
\hline CI & $\mathrm{L} \cdot \mathrm{min}^{-1} \cdot \mathrm{m}^{-2}$ & 11 & $2.6 \pm 0.6$ & $3.3 \pm 0.4$ & $3.0 \pm 0.4$ & $<0.0001$ & 0.11 \\
\hline PVR & dyn $\cdot s \cdot \mathrm{cm}^{-5}$ & 11 & $778 \pm 313$ & $410 \pm 197$ & $383 \pm 258$ & $<0.0001$ & 0.36 \\
\hline $\mathrm{Pa}_{\mathrm{a}, \mathrm{O}_{2}}$ & $\mathrm{kPa}$ & 21 & $7.4 \pm 1.0$ & $8.3 \pm 1.5$ & $10.1 \pm 1.6$ & 0.019 & $<0.0001$ \\
\hline $\mathrm{Pa}_{\mathrm{a}} \mathrm{CO}_{2}$ & $\mathrm{kPa}$ & 21 & $4.7 \pm 0.6$ & $5.0 \pm 0.5$ & $5.0 \pm 0.5$ & 0.07 & 0.98 \\
\hline$P \mathrm{~A}-\mathrm{a}, \mathrm{O}_{2}$ & $\mathrm{kPa}$ & 21 & $6.5 \pm 1.6$ & $5.3 \pm 1.8$ & $3.0 \pm 1.6$ & 0.0059 & $<0.0001$ \\
\hline$P_{\overline{\mathrm{v}}, \mathrm{O}_{2}}$ & $\mathrm{kPa}$ & 15 & $4.6 \pm 0.5$ & $4.9 \pm 0.4$ & $\begin{array}{l}5.2 \pm 0.4 \\
(n=11)\end{array}$ & 0.02 & 0.014 \\
\hline Absolute shunt & $\%$ & 15 & $10 \pm 3$ & $11 \pm 4$ & $9 \pm 3 \quad(n=7)$ & 0.50 & 0.37 \\
\hline VC & $\%$ pred & 12 & $105 \pm 15$ & $81 \pm 18$ & $96 \pm 17$ & $<0.0001$ & 0.001 \\
\hline FEV1/FVC & $\%$ & 12 & $76 \pm 7$ & $77 \pm 12$ & $79 \pm 9$ & 0.86 & 0.51 \\
\hline TLC & $\%$ pred & 12 & $104 \pm 19$ & $85 \pm 19$ & $98 \pm 23$ & 0.0004 & 0.026 \\
\hline FRC & $\%$ pred & 12 & $105 \pm 20$ & $91 \pm 22$ & $101 \pm 29$ & 0.0005 & 0.2 \\
\hline TL,CO & $\%$ pred & 12 & $60 \pm 9$ & $47 \pm 12$ & $58 \pm 11$ & 0.0143 & 0.0006 \\
\hline H-J & & 21 & & & & & \\
\hline Grade 1 & & & & 2 & 5 & & \\
\hline Grade 2 & & & 1 & 7 & 12 & & \\
\hline Grade 3 & & & 8 & 10 & 3 & & \\
\hline Grade 4 & & & 10 & 1 & 1 & & \\
\hline Grade 5 & & & 2 & 1 & & & \\
\hline
\end{tabular}

Values are presented as mean \pm SD. *: two-tailed paired t-tests. For abbreviations see legend to tables 1 and $2.1 \mathrm{kPa}=0.133$ $\mathrm{mmHg}$. 
to $3.3 \pm 0.6 \mathrm{~L} \cdot \mathrm{min}^{-1} \cdot \mathrm{m}^{-2}$. PVR decreased from $781 \pm 290$ to $399 \pm 177$ dyn $\cdot \mathrm{s} \cdot \mathrm{cm}^{-5}$, and the change in PVR was more than $30 \%$ in 18 cases. $P \mathrm{a}_{1} \mathrm{O}_{2}$ increased from $7.4 \pm 1.0 \mathrm{kPa}$ $(56 \pm 8 \mathrm{mmHg})$ to $8.3 \pm 1.5 \mathrm{kPa}(62 \pm 12 \mathrm{mmHg}) . P \mathrm{AA}-\mathrm{a}, \mathrm{O}_{2}$ decreased and $P \overline{\mathrm{v}}, \mathrm{O}_{2}$ increased (table 4$)$. In only seven of 21 patients, the increase in $P \mathrm{a}, \mathrm{O}_{2}$ was $>1.3 \mathrm{kPa}(10$ $\mathrm{mmHg}$ ). The remaining 14 patients were classified as moderate results at that time. Vital capacity (VC), total lung capacity (TLC), functional residual capacity (FRC) and TL,CO decreased compared to preoperative data. Symptomatic improvement according to H-J classification was also observed (table 4). Perfusion scans and pulmonary angiograms showed significant improvement. In 11 of the 21 cases, perfusion scans showed hyperperfused areas at the endarterectomized segments and new hypoperfused areas at the segments where endarterectomy was not attempted (fig. 1b). Four surgical deaths occurred during the early postoperative period, a $16 \%$ mortality rate, and this was reduced to $9 \%$ (1 of 11 cases) when considering only the last 5 yrs (from 1992 to 1996). Two patients died because they could not be weaned from extracorporeal circulation after a median sternotomy approach. The other two patients died of right heart failure postunilateral thoracotomy approach. One patient developed postoperative cerebral infarction. Severe reperfusion pulmonary oedema [25] was not observed in the present series.

\section{Long-term follow-up}

Right heart catheterization data, available in 11 patients at 6-24 months after surgery, showed sustained haemodynamic improvement. $P \mathrm{a}, \mathrm{O}_{2}$ increased and $P$ Aa, $\mathrm{O}_{2}$ decreased $\left(\mathrm{Pa}_{\mathrm{a}} \mathrm{O}_{2}: 8.3 \pm 1.5 \mathrm{kPa}(62 \pm 12 \mathrm{mmHg})\right.$ to $10.1 \pm 1.6 \mathrm{kPa}(76 \pm 12 \mathrm{mmHg}), P \mathrm{~A}-\mathrm{a}, \mathrm{O}_{2}: 5.3 \pm 1.8 \mathrm{kPa}(39 \pm 13$ $\mathrm{mmHg})$ to $3.0 \pm 1.6 \mathrm{kPa}(22 \pm 12 \mathrm{mmHg}))$ during the longterm follow-up period as well (table 4). Further symptomatic improvement (H-J) was also observed. All 21 patients who survived were reclassified, and 16 patients were classified into the excellent results group. They were categorized as NYHA class 1 or 2 and belonged to $\mathrm{H}-\mathrm{J}$ grade 1 or 2 . VC, FRC, TLC, and TL,CO, which declined at 1 month postsurgery, returned to the preoperative levels. Perfusion scans were re-examined in seven of 11 patients who had shown vascular steal phenomenon at 1 month after surgery. In six of the seven cases (85\%), hypoperfused areas were resolved and more homogeneous perfusion was observed (fig. 1c). All 16 patients of the excellent results group could return to a normal active life. Even the remaining five patients of the moderate results group demonstrated improved activity in daily life compared to their preoperative status, although one patient showed transient right heart failure at 18 months after surgery and another who had anticardiolipin antibody showed recurrent embolic episodes. None of these 21 patients died during their follow-up periods of 1-10 yrs, and all patients were taking warfarin.

\section{Preoperative risk factors}

Various preoperative factors were compared to analyse preoperative risk factors (table 5). PVR and CI were a)

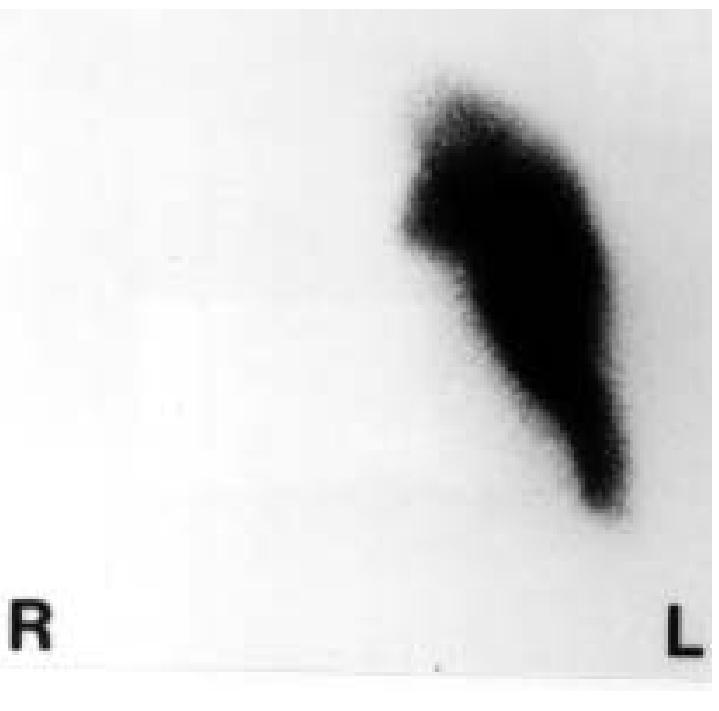

b)

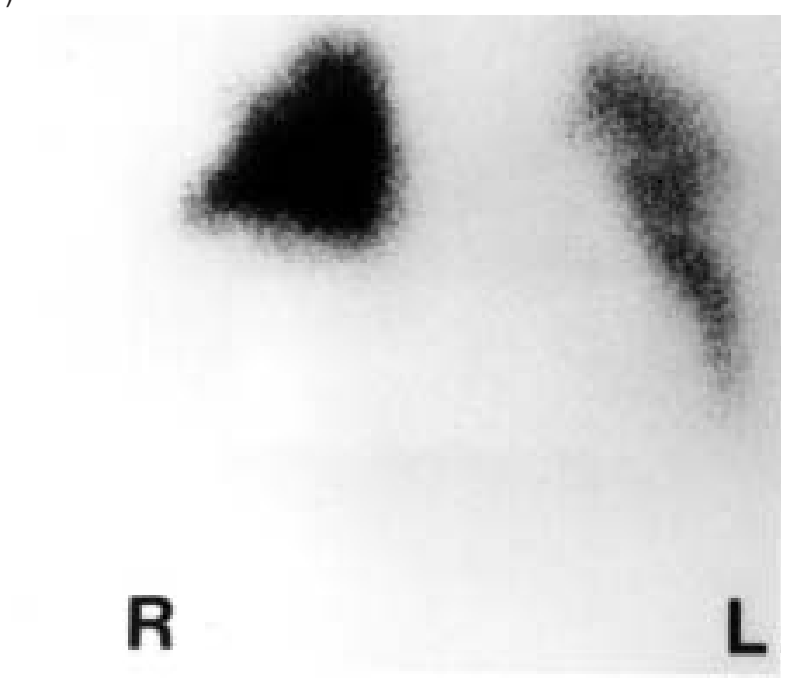

c)

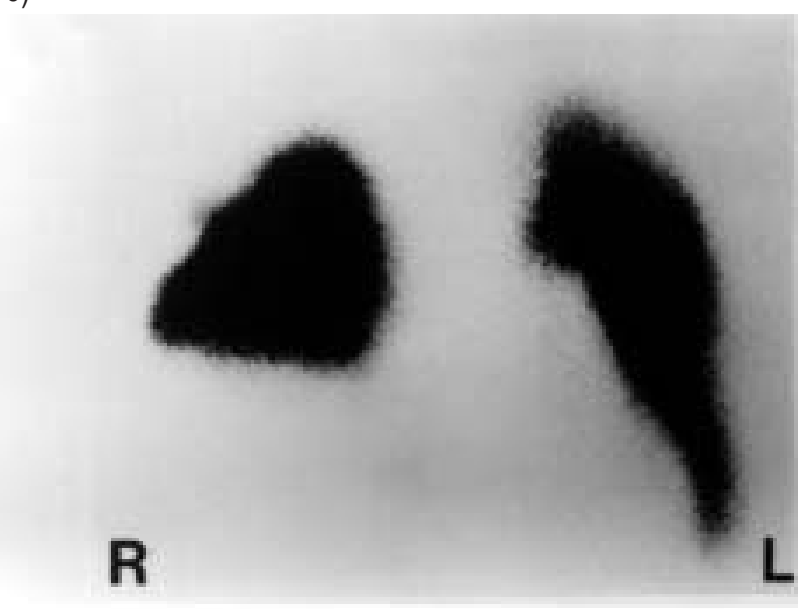

Fig. 1. - a) Preoperative perfusion scan showing complete perfusion defect in the right lung filed. $\mathrm{Pa}_{\mathrm{a}} \mathrm{O}_{2}$ was 57 torr. b) Perfusion scan at 1 month postsurgery, showing relative hypoperfusion in the left lung. $P \mathrm{a}_{1} \mathrm{O}_{2}$ was 65 torr. c) Perfusion scan at 6 months after surgery, showing resolution of left hypoperfusion. $\mathrm{Pa}_{\mathrm{a}} \mathrm{O}_{2}$ was 75 torr. R: right; L: left. 
Table 5. - Comparison of preoperative parameters between survivors and nonsurvivors

\begin{tabular}{|c|c|c|c|}
\hline & $\begin{array}{l}\text { Survivors } \\
\quad(\mathrm{n}=21)\end{array}$ & $\begin{array}{c}\text { Nonsurvivors } \\
(\mathrm{n}=4)\end{array}$ & p-value* \\
\hline Age & $52 \pm 13$ & $47 \pm 18$ & 0.53 \\
\hline $\begin{array}{l}\text { Duration of } \\
\text { symptoms months }\end{array}$ & $26 \pm 19$ & $38 \pm 38$ & 0.28 \\
\hline $\mathrm{mmHg}$ & $45 \pm 7$ & $54 \pm 7$ & 0.054 \\
\hline $\mathrm{L} \cdot \mathrm{min}^{-1} \cdot \mathrm{m}^{-2}$ & $2.6 \pm 0.5$ & $1.8 \pm 0.3$ & 0.0033 \\
\hline $\mathrm{dyn} \cdot \mathrm{s} \cdot \mathrm{cm}^{-5}$ & $791 \pm 287$ & $1342 \pm 300$ & 0.0019 \\
\hline$P \mathrm{a}, \mathrm{O}_{2} \quad \mathrm{kPa}$ & $7.4 \pm 1.0$ & $8.5 \pm 1.2$ & 0.08 \\
\hline$P_{\overline{\mathrm{v}}, \mathrm{O}_{2}} \quad \mathrm{kPa}$ & $4.4 \pm 0.5$ & $4.0 \pm 0.2$ & 0.09 \\
\hline
\end{tabular}

Values are presented as mean $\pm \mathrm{SD}$. *: two-tailed paired t-tests. For abbreviations see legend to tables 1 and $2.1 \mathrm{kPa}=0.133$ $\mathrm{mmHg}$.

Table 6. - Comparison of preoperative parameters between excellent results and poor results groups during follow-up

\begin{tabular}{lccl}
\hline & $\begin{array}{c}\text { Excellent results } \\
\text { group } \\
(\mathrm{n}=16)\end{array}$ & $\begin{array}{c}\text { Poor results } \\
\text { group } \\
(\mathrm{n}=9)\end{array}$ & p-value* \\
\hline Age yrs & $50 \pm 12$ & $53 \pm 17$ & 0.7 \\
Duration of & $25 \pm 20$ & $33 \pm 26$ & 0.38 \\
symptoms months & & & \\
$\bar{P}$ pa mmHg & $44 \pm 7$ & $52 \pm 7$ & 0.013 \\
$\mathrm{CI} \mathrm{L} \cdot \mathrm{min}^{-1} \cdot \mathrm{m}^{-2}$ & $2.6 \pm 0.5$ & $2.3 \pm 0.6$ & 0.14 \\
$\mathrm{PVR} \mathrm{dyn} \cdot \mathrm{s} \cdot \mathrm{cm}^{-5}$ & $735 \pm 223$ & $1135 \pm 398$ & 0.0036 \\
$P \mathrm{a}, \mathrm{O}_{2} \mathrm{kPa}$ & $7.4 \pm 0.9$ & $8.0 \pm 1.3$ & 0.16 \\
$P \overline{\mathrm{v}}, \mathrm{O}_{2} \mathrm{kPa}$ & $4.4 \pm 0.5$ & $4.3 \pm 0.5$ & 0.48 \\
$\mathrm{VC} \%$ pred & $106 \pm 12$ & $88 \pm 12$ & 0.0018 \\
$\mathrm{FEV} 1 / \mathrm{FVC} \%$ & $76 \pm 7$ & $75 \pm 9$ & 0.73 \\
$\mathrm{TLC} \%$ pred & $107 \pm 13$ & $88 \pm 16$ & 0.0044 \\
FRC \% pred & $109 \pm 10$ & $93 \pm 20$ & 0.024 \\
$\mathrm{TL}, \mathrm{CO} \%$ pred & $58 \pm 19$ & $53 \pm 16$ & 0.46 \\
$\mathrm{H}-\mathrm{J}$ & Grade 2: 1, & Grade 3: 5, & 0.026 \\
& Grade 3: 6, & Grade 4: 1, & \\
& Grade 4: 9 & Grade 5: 3 & \\
\hline
\end{tabular}

Values are presented as mean \pm SD. *: all but H-J were made using unpaired t-tests and $\mathrm{H}-\mathrm{J}$ was made using chi-squared test. For abbreviations see legend to tables 1 and 2.

significantly worse in nonsurvivors compared to survivors. The comparisons of various parameters between the excellent and poor results groups are listed in table 6. $\bar{P}$ pa, PVR, and H-J were significantly worse in the poor results group. The averaged values of VC, FRC and TLC were almost normal in both groups, but those of the poor results group were significantly lower than those of the excellent results group. Twelve patients had PVR >900 dyn $\cdot s \cdot \mathrm{cm}^{-5}$ and all nonsurvivors had PVR $>900 \mathrm{dyn} \cdot \mathrm{s} \cdot \mathrm{cm}^{-5}$. Mortality rate and the incidence of poor results in the severe $\mathrm{PH}$ group (PVR $>900 \mathrm{dyn} \cdot \mathrm{s} \cdot \mathrm{cm}^{-5}$ ) were significantly higher than those in the moderate $\mathrm{PH}$ group (mortality: severe PH group 33\% versus moderate $\mathrm{PH}$ group $0 \%, \mathrm{p}=0.039$; poor results: severe $\mathrm{PH}$ group $58 \%$ versus moderate $\mathrm{PH}$ group $15 \%, \mathrm{p}=0.041$ ).

\section{Discussion}

The results of this study are summarized as follows: 1) significant haemodynamic improvement was observed at 1 month after surgery, but the improvement of gas exchange was delayed, with further improvements of symptoms and gas exchange being observed at 6-24 months of follow-up; 2) mortality rate was 16\%; and 3) severe haemodynamic impairment (PVR $>900 \mathrm{dyn} \cdot \mathrm{s} \cdot \mathrm{cm}^{-5}$ ) was related to mortality or poor postoperative results. Preoperative restrictive pulmonary functional parameters were significantly lower in the poor results group.

Females outnumbered males by $1.8: 1$. This tendency was similar to that of a French study (3:1) [18], but different from a USA (1:1.6) [6] and a German study $(1: 1.1)$ [8]. Only $36 \%$ of the patients had a history of deep vein thrombosis. This frequency was not dissimilar to that in the USA (40\%) and in Germany (48\%). The frequency of positive anticardiolipin antibody was $25 \%$, similar to the French study (24\%) and higher than the German study (9\%). Although it is unknown whether a history of varicose veins or pelvic surgery is causally related to CTEPH, $31 \%$ of our female patients had this history.

In our study, we found a time discrepancy between the improvement of pulmonary haemodynamics and gas exchange data after PTE. A slight improvement of hypoxaemia in the early postoperative period was accompanied by improvements in CI, $P A-a, O_{2}$ and $P \overline{\mathrm{v}}, \mathrm{O}_{2}$ These results are consistent with those of KAPITAN and coworkers [26, 27]. They reported that hypoxaemia of CTEPH is the consequence of a moderate ventilationperfusion abnormality, with the hypoxic effect being considerably amplified by a lowered $P \overline{\mathrm{v}}, \mathrm{O}_{2}$ and that PTE improved gas exchange both by improving the ventilation-perfusion relationship and increasing cardiac output. However, the improvement of hypoxaemia was unsatisfactory in spite of the significant haemodynamic improvement at 1 month postsurgery. The hypoxaemia significantly improved at 6 months to 2 yrs after surgery without any significant change in pulmonary haemodynamics. There are several possible explanations for these findings.

Firstly, as for the recovery of VC, TLC and TL,CO at 1 month postsurgery after the initial decrease, restrictive pulmonary functional impairment due to the direct effect of thoracotomy, postoperative atelectasis, diaphragm elevation, pleural adhesion and general fatigue might cause ventilation-perfusion abnormality, resulting in prolonged hypoxaemia. Diffusion limitation due to postoperative pulmonary oedema could also be one of the mechanisms of hypoxaemia, although there was no such evidence on chest radiographs. It is most likely that this restrictive impairment and diffusion limitation contributed to prolonged hypoxaemia with elevated $\mathrm{PA}-\mathrm{a}, \mathrm{O}_{2}$ during the early postoperative period.

Secondly, although we could not examine the ventilation-perfusion relationship by the multiple inert gas technique [26, 27], we observed improvement in perfusion heterogeneity from the early postoperative period through long-term follow-up. In 11 of 21 survivors, 1 month postsurgery perfusion scans showed heterogeneous perfusion consisting of hyperperfused areas which had been endarterectomized, as well as new hypo-perfused areas that had not been surgically approached. The new hypoperfused areas were regarded as the result of the vascular steal phenomenon described by Olman et al. [28]. In $85 \%$ of the cases whose perfusion scans were re-evaluated in the follow-up period, the vascular steal was then resolved and more homogeneous 
perfusion was observed at 6 months to 2 yrs in accordance with improvement of hypoxaemia. OLMAN et al. [28] explained that the reason for this phenomenon was a redistribution of pulmonary arterial resistance induced by PTE. Moser et al. [29] reported that postoperative steal improved in $96 \%$ of patients and $86 \%$ of the stolen segments. It is reasonable to consider that the ventilation-perfusion mismatch on perfusion scans could contribute to prolonged hypoxaemia with elevated $\mathrm{PA}-\mathrm{a}, \mathrm{O}_{2}$ during the early postoperative period and the improvement of ventilation-perfusion relationship could contribute to resolution of hypoxaemia over the longer term.

Thirdly, a study in Germany recently reported a persistent decrease in pulmonary vascular resistance and improvement in right ventricular function during follow-up after thromboendarterectomy [8]. However, our study found that there was only a time discrepancy between the improvement of pulmonary haemodynamics and gas exchange, and both were finally attained.

Fourthly, the absolute shunt ratio during $100 \% \mathrm{O}_{2}$ breathing $(10 \pm 4 \%)$ was somewhat higher than expected. We do not know exactly why it was higher than in the studies of KAPITAN and co-workers [26, 27]. In their studies, only one patient had elevated shunt ratio and it did not improve postoperatively. The mechanisms of shunt due to pulmonary embolism might be explained as follows: 1) pulmonary infarction; 2) development of areas of atelectasis distal to the embolic obstruction of the vascular bed induced by probable loss of surfactant, haemorrhage and pneumoconstriction; 3) opening of pre-existing pulmonary arterial venous anastomoses with high pulmonary arterial pressure; and 4) development of a patent foramen ovale [30]. However, the shunt ratio in our series did not improve postoperatively, so the first and second factors might be related to our results.

The mortality rate in the present study was $16 \%$, and this was reduced to $9 \%$ when focusing only on the most recent 5 yrs (from 1992 to 1996). The mortality rate in our study by both lateral and median approaches was higher than the San Diego group, but was similar to others (table 7). To assess the effectiveness of surgery, we divided patients into groups of excellent and poor results. Five of $21(24 \%)$ survivors belonged to the poor results group, who were categorized as NYHA 3 or 4 , even during follow-up. These results were unsatisfactory compared to the San Diego group (only $5 \%$ belonged to NYHA 3 or 4) [5], based on the fact that the severity of pulmonary hypertension in our series was similar to theirs (PVR $880 \pm 350$ versus $901 \pm 467 \mathrm{dyn} \cdot \mathrm{s} \cdot \mathrm{cm}^{-5}$ ) [5]. Pulmonary haemodynamics before surgery were significantly worse in nonsurvivors or in the poor results group. The level of PVR $>900 \mathrm{dyn} \cdot \mathrm{s} \cdot \mathrm{cm}^{-5}$ significantly contributed to nonsurvivors $(\mathrm{p}=0.039)$ or to poor results $(\mathrm{p}=0.041)$. These data are similar to those of DAILY et al. [4]. They reported that the level of PVR $>865$ dyn $\cdot \mathrm{s} \cdot \mathrm{cm}^{-5}$ suggested increased hospital mortality as a preoperative factor.

In addition, the thromboemboli of two nonsurvivors and two survivors with poor results in our series were limited to segmental arteries or were "too distal" for surgical accessibility [19]. JAMIESON et al. [6] recently reported that significant residual causes of mortality for PTE are the inability to reduce pulmonary arterial pressure as a result of distal disease that proves inaccessible, and unrelenting postoperative reperfusion oedema.

As for the location of thrombi in our series, most of those which were surgically accessible were located on only one side. The thrombi on the contralateral side were mostly located in subsegmental arteries or were too fragile to be retracted. In other words, we could remove the thrombi from only one side (mainly right lung), but could not retract the thrombi, or could retract only a few, from the contralateral side. A difference in the distribution of thrombi as well as a lack of experience compared to the San Diego group might be related to the high frequency of our poor results.

Significantly, lower values of restrictive pulmonary functional parameters were related to poor results. The cause of restrictive change in CTEPH is not well explained, but fibrotic change and pleural adhesion induced by pulmonary atelectasis and/or infarction might be involved. Worsening of pulmonary restrictive pattern even after surgery could result in areas of relatively low ventilation-perfusion and partially contribute to the unsatisfactory and delayed resolution of hypoxaemia.

We had five nonoperated cases with $\bar{P}$ pa $\geq 30 \mathrm{mmHg}$. Three died despite home oxygen therapy and warfarin. The time from diagnosis to death was 17,18 and 31 months. RiEDEL et al. [31] showed that PH progressed further when initial $\bar{P}$ pa was greater than $30 \mathrm{mmHg}$. However, we also had three nonoperated cases with $\bar{P}_{\text {pa }}$ of $30 \mathrm{mmHg}$ to $50 \mathrm{mmHg}$ at the first catheterization, and their $\bar{P}$ pa declined from $20 \mathrm{mmHg}$ to $30 \mathrm{mmHg}$ after medical treatment. The patients with identified episodes of pulmonary embolism and moderately raised $\mathrm{PH}$ should be medically treated for at least 6 months. Our current criterion $(\bar{P}$ pa $\geq 30 \mathrm{mmHg}$ after medical treatment $)$ therefore seems reasonable. We believe that PTE has clearly improved the prognosis of patients with CTEPH. The favourable effect of PTE on gas exchange and pulmonary haemodynamics was confirmed, and improvements

Table 7. - Surgical results for chronic pulmonary thromboembolism reported in the literature

\begin{tabular}{|c|c|c|c|c|c|}
\hline Institute & First author & Year & [Ref.] & $\mathrm{n}$ & Mortality rate $\%$ \\
\hline Duke University & ChITwood & 1985 & [10] & $\begin{array}{c}85 \\
\text { (review of literature) }\end{array}$ & 22 \\
\hline La Pitie Hospital & JAULT & 1989 & [12] & 33 & 20 \\
\hline \multirow[t]{3}{*}{ UCSD Medical Center } & DAILY & 1990 & [4] & 127 & 13 \\
\hline & JAMIESON & 1993 & [6] & 150 & 8 \\
\hline & & 1995 & [7] & 357 & 5 \\
\hline Antoine Beclere Hospital & SimONNEAU & 1995 & [19] & 11 & 18 \\
\hline Johannes Gutenberg-University Hospital & MAYER & 1996 & [8] & 199 & 24 \\
\hline University of Illinois & HARTZ & 1996 & [9] & 34 & 23 \\
\hline
\end{tabular}

UCSD: University of California, San Diego. 
of daily activity and quality of life were also apparent in the excellent results group. Although Simonneau et al. [19] reported beneficial results of lung transplantation in patients with "too distal" thrombi or in severely compromised patients, lung transplantation has not been legally or socially accepted in Japan. Only PTE may be performed, even in high-risk patients. Moreover, PALLA et al. [32] showed that the patients with CTEPH usually had no diagnosis and treatment for the several retrospectively identified episodes of pulmonary embolism. Our future goals will be to improve the diagnosis and treatment of pulmonary embolism, and to further improve diagnostic accuracy of chronic thromboembolic pulmonary hypertension and surgical outcome.

\section{References}

1. Moser KM, Spragg RG, Utley J, Daily PO. Chronic thrombotic obstruction of major pulmonary arteries: results of thromboendarterectomy in 15 patients. Ann Intern Med 1983; 99: 299-305.

2. Daily PO, Dembitsky WP, Peterson KL, Moser KM. Modifications of techniques and early results of pulmonary thromboendarterectomy for chronic pulmonary embolism. J Thorac Cardiovasc Surg 1987; 93: 221-233.

3. Moser KM, Auger WR, Fedullo PF. Chronic major-vessel thromboembolic pulmonary hypertension. Circulation 1990: 81: 1735-1743.

4. Daily PO, Dembitsky WP, Iversen S, Moser KM, Auger W. Risk factors for pulmonary thromboendarterectomy. J Thorac Cardiovasc Surg 1990; 99: 670-678.

5. Moser KM, Auger WR, Fedullo PF, Jamieson SW. Chronic thromboembolic pulmonary hypertension: clinical picture and surgical treatment. Eur Respir J 1992; 5: $334-342$.

6. Jamieson SW, Auger WR, Fedullo PF, et al. Experience and results with 150 pulmonary thromboendarterectomy operations over a 29-month period. J Thorac Cardiovasc Surg 1993; 106: 116-127.

7. Jamieson SW. Treatment of pulmonary hypertension due to chronic pulmonary thromboembolism. Jpn $J$ Phlebol 1995; 6: 1-12.

8. Mayer E, Dahm M, Hake U, et al. Mid-term results of pulmonary thromboendarterectomy for chronic pulmonary hypertension. Ann Thorac Surg 1996; 61: 1788-1792.

9. Hartz RS, Byrne JG, Levtsky S, Park J, Rich S. Predictors of mortality in pulmonary thromboendarterectomy. Ann Thorac Surg 1996; 62: 1255-1260.

10. Chitwood WR, Lyerly HK, Sabiston DC. Surgical management of chronic pulmonary embolism. Ann Surg 1985; 201: 11-26.

11. Cabrol C, Cabrol A, Acar J, et al. Surgical correction of chronic postembolic obstructions of the pulmonary arteries. J Thorac Cardiovasc Surg 1978; 76: 620-628.

12. Jault F, Cabrol C. Surgical treatment for chronic pulmonary thromboembolism. Herz 1989; 14: 192-196.

13. Nakajima N, Ando M, Adachi S, Kasegawa H. Surgical treatment of pulmonary thromboembolism. Jpn J Thorac D 1988; 26: 487-492.

14. Nakagawa Y, Masuda M, Shiihara H, et al. Surgical results of pulmonary thromboendarterectomy for chronic pulmonary thromboembolism. J JPN Assoc Thorac Surg 1991; 39: 192-199.
15. Nakagawa Y. Surgery for chronic thromboembolic pulmonary hypertension. International Congress of Phlebology, Greece 1996: 393-396.

16. Takanashi M, Tanaka N, Sawa S, Mukai K, Ishikawa $\mathrm{T}$. The results of three cases of unilateral pulmonary embolectomy through right thoracotomy approach for chronic pulmonary embolism. J Cardiovasc Surg 1995; 36: 195-198.

17. Kuriyama T. Clinical aspects of precapillary pulmonary hypertension. Jpn J Thorac D 1992; 30: 3-11.

18. Bengtsson L, Henze A, Holmgren A, Bjork VO. Thromboendarterectomy in chronic pulmonary embolism: reports of 3 cases. Scand J Thorac Cardiovasc Surg 1986; 20: $67-70$.

19. Simonneau G, Azarian R, Brenot F, Dartevelle PG, Musset D, Duroux P. Surgical management of unresolved pulmonary embolism: a personal series of 72 patients. Chest 1995; 107: 52s-55s.

20. Mieno T, Aoki S, Sugama Y, et al. Incidence of pulmonary thromboembolism in Japan. Jpn J Thorac Dis 1988; 26: 448-456.

21. Auger WR, Fedullo PF, Moser KM, Buchbinder M, Peterson KL. Chronic major-vessel thromboembolic pulmonary artery obstruction: appearance at angiography. Radiology 1992; 182: 393-398.

22. Hugh-Jones P. A simple standard exercise test and its use for measuring exertion dyspnoea. Br Med J 1952; 65-71.

23. Harris EN, Gharavi AE, Boey ML, et al. Anticardiolipin antibodies: Detection by radioimmunoassay and association with thrombosis in systemic lupus erythematosus. Lancet 1983; ii: 1211-1214.

24. Prediletto R, Paoletti P, Fornai E, et al. Natural course of treated pulmonary embolism. Evaluation by perfusion lung scintigraphy, gas exchange, and chest roentgenogram. Chest 1990; 97: 554-561.

25. Levinson RM, Shure D, Moser KM. Reperfusion pulmonary edema after pulmonary artery thromboendarterectomy. Am Rev Respir Dis 1986; 134: 1241-1245.

26. Kapitan KS, Buchbinder M, Wagner PD, Moser KM. Mechanisms of hypoxemia in chronic thromboembolic pulmonary hypertension. Am Rev Respir Dis 1989; 139: $1149-1154$.

27. Kapitan KS, Clausen JL, Moser KM. Gas exchange in chronic thromboembolism after pulmonary thromboendarterectomy. Chest 1990; 98: 14-19.

28. Olman MA, Auger WR, Fedullo PF, Moser KM. Pulmonary vascular steal in chronic thromboembolic pulmonary hypertension. Chest 1990; 98: 1430-1434.

29. Moser KM, Metersky ML, Auger WR, Fedullo PF. Resolution of vascular steal after pulmonary thromboendarterectomy. Chest 1993; 104: 1441-1444.

30. Sergysels R. Pulmonary gas exchange abnormalities in pulmonary embolism. In: Morpurgo M, ed. Pulmonary Embolism. New York, Marcel Dekker Inc, 1994; 89-96.

31. Riedel M, Stanek V, Widimsky J, Prerovsky I. Longterm follow-up of patients with pulmonary thromboembolism: late prognosis and evolution of hemodynamic and respiratory data. Chest 1982; 81: 151-158.

32. Palla A, Formichi B, Santolicandro A, Di Ricco G, Giuntini C. From not detected pulmonary embolism to diagnosis of chronic thromboembolic pulmonary hypertension: a retrospective study. Respiration 1993; 60: 9-14. 